\title{
DETERMINATION OF THE OPTIMAL SCANNING STEP FOR EVALUATION OF IMAGE RECONSTRUCTION QUALITY IN MAGNETOACOUSTIC TOMOGRAPHY WITH MAGNETIC INDUCTION
}

\author{
Adam Ryszard Zywica, Marcin Ziolkowski \\ West Pomeranian University of Technology, Faculty of Electrical Engineering, Department of Electrical and Computer Engineering, Szczecin, Poland
}

Abstract. Magnetoacoustic Tomography with Magnetic Induction (MAT-MI) is a new hybrid imaging modality especially dedicated for non-invasive electrical conductivity imaging of low-conductivity objects such as e.g. biological tissues. The purpose of the present paper is to determine the optimal scanning step assuring the best quality of image reconstruction. In order to resolve this problem a special image reconstruction quality indicator based on binarisation has been applied. Taking into account different numbers of measuring points and various image processing algorithms, the conditions allowing successful image reconstruction have been provided in the paper. Finally, the image reconstruction examples for objects' complex shapes have been analysed.

Keywords: image reconstruction, image processing algorithms, medical diagnostic imaging, magnetoacoustic effects, magnetoacoustic tomography with magnetic induction

\section{OKREŚLENIE OPTYMALNEGO KROKU SKANOWANIA DO OCENY JAKOŚCI REKONSTRUKCJI OBRAZU W TOMOGRAFII MAGNETOAKUSTYCZNEJ ZE WZBUDZENIEM INDUKCYJNYM}

\begin{abstract}
Streszczenie. Tomografia magnetoakustyczna ze wzbudzeniem indukcyjnym (MAT-MI) to nowa hybrydowa technika obrazowania dedykowana szczególnie do nieinwazyjnego obrazowania obiektów o niskiej konduktywności elektrycznej, takich jak na przyktad tkanki biologiczne. Celem niniejszej pracy jest określenie optymalnego kroku skanowania zapewniającego najlepsza jakość rekonstrukcji obrazu. W celu rozwiąania tego problemu zastosowano specjalny wskaźnik jakości rekonstrukcji obrazu bazujący na binaryzacji. W artykule przedstawiono warunki umożliwiajace pomyślne zrekonstruowanie obrazu biorac pod uwage różna liczbe punktów pomiarowych oraz różne algorytmy przetwarzania obrazu. W końcowym etapie pracy przeanalizowano przykłady rekonstrukcji obrazu dla obiektów o bardziej złożonych kształtach.
\end{abstract}

Słowa kluczowe: rekonstrukcja obrazu, algorytmy przetwarzania obrazu, diagnostyczne obrazowanie medyczne, efekty magnetoakustyczne, tomografia magnetoakustyczna ze wzbudzeniem indukcyjnym

\section{Introduction}

Magnetoacoustic Tomography with Magnetic Induction (MAT-MI) is a new hybrid modality dedicated for non-invasive imaging of low-conductivity objects' internal structure, especially designated to use in medical diagnostics or in non-destructive testing of materials. MAT-MI is characterised by a good spatial resolution, high contrast and overcomes the unwanted screening effect which is often found in other tomographic techniques $[5,8$, $10]$.

The MAT-MI method can be divided into two main parts, namely: so-called forward and inverse problems. The result of the first part is obtaining and recording the sound pressure generated inside the low-conductivity object. The ultrasonic signals are collected by piezoelectric transducers (during an experiment) or calculated at measuring points - which in a present simulation study are the transducers' equivalents. The latter part consists of two steps, i.e. reconstructing the distribution of the Lorentz force divergence, and finally, the imaging of the electrical conductivity distribution $[5,9]$.

MAT-MI, in the principle, uses electromagnetic and acoustic field theory. In this technique an object to be imaged is placed in static and time-varying (pulsed) external magnetic fields (an arrangement schematically has been shown in Fig. 1). Accordingly, due to the electromagnetic induction, eddy currents are induced. Consequently, the object emits acoustic waves through the Lorenz force generated as result of interaction between static magnetic field and eddy currents. The propagated acoustic waves are used for electrical conductivity image reconstruction [5].

The purpose of the presented study is to determine the optimal scanning step which is the equivalent of ultrasonic pressure measuring points' number. In order to resolve this problem a special image reconstruction quality indicators based on binarisation have been applied. Finally, the image reconstruction examples for objects' complex shapes have been analysed and the reconstruction of the Lorentz force divergence has been achieved. Taking into account different numbers of measuring points and various image processing algorithms, the conditions allowing successful image reconstruction have been provided.

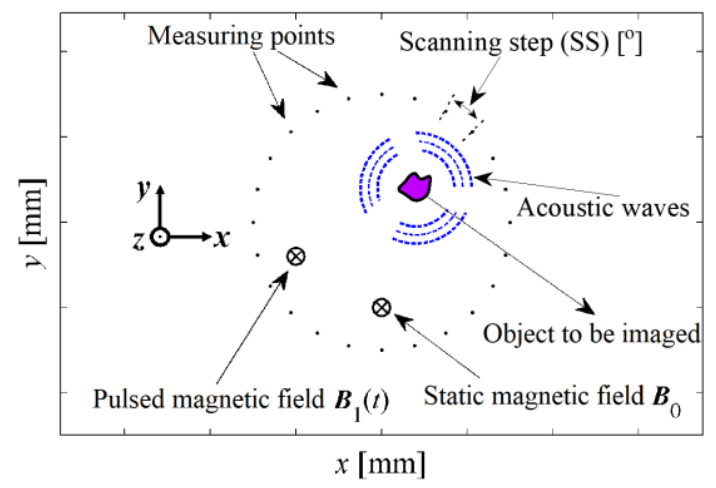

Fig. 1. Schematic diagram of 2D MAT-MI concept

\section{Image reconstruction quality}

In order to determine the conditions allowing for successful image reconstruction an assessment of the quality of the reconstructed images must be made. In this case, the image reconstruction quality should be understood by the similarity between the reconstructed image and the original image of an object. There are two kinds of quality assessment: subjective assessment (a method based on estimation of image quality by a human) and objective assessment (considered in this paper) where the goal is to implement and use quality indicator that can predict perceived image quality automatically. In practice, an objective image quality metric can be employed to determine the optimal value of scanning step SS which determines a required minimal scanning resolution assuring the best quality of image reconstruction. Finally, information obtained during the simulation studies can be used subsequently in experiments to properly calibrate a measuring system [7].

In tomography, various approaches and correlated indicators are commonly used in image processing approaches, e.g. an image feature extraction (shape, curve, texture and histogram). In this paper a straight image comparison, based on comparing binary images globally, has been applied [1]. The block diagram of a quality estimation of an image reconstruction is shown in Fig. 2. 


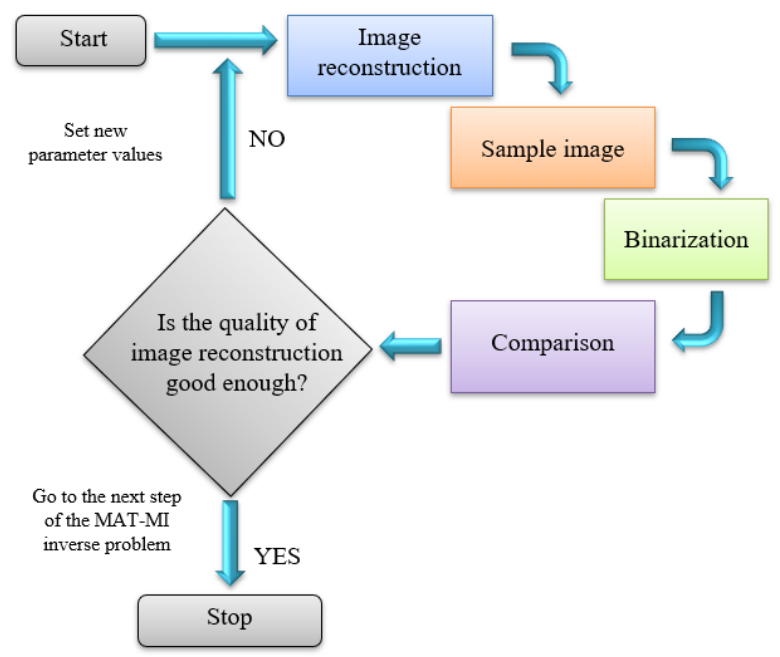

Fig. 2. Block diagram of reconstruction quality evaluation algorithm

In order to obtain sample images, the first step of the MAT-MI inverse problem ought to be conducted. The Lorentz force divergence can be reconstructed using time reversal technique which is one of the ultrasound imaging modalities [5, 9]. The resulting sample images (stored in grayscale) are subjected to a binarisation and then compared with the original image of the object. The binarisation process has been performed with the help of Matlab's function imbinarize. The function uses Otsu's method, which chooses the threshold value to minimize the interclass variance of the threshold black and white pixels (global thresholding method) [6].

The most appropriate and natural ways to compare binary images is the statistical approach using such indicators as: positive predictive value (PPV, precision), negative predictive value (NPV), true positive rate (TPR, sensitivity), true negative rate (TNR, specificity or selectivity) and accuracy (ACC) which are derivatives from so-called confusion matrix (also called as error matrix). PPV, NPV, TPR, TNR and ACC can be determined by the following expressions [4]:

$$
\begin{gathered}
\mathrm{PPV}=\frac{\mathrm{TP}}{\mathrm{TP}+\mathrm{FP}}, \\
\mathrm{NPV}=\frac{\mathrm{TN}}{\mathrm{TN}+\mathrm{FN}}, \\
\mathrm{TPR}=\frac{\mathrm{TP}}{\mathrm{TP}+\mathrm{FN}}, \\
\mathrm{TNR}=\frac{\mathrm{TN}}{\mathrm{TN}+\mathrm{FP}}, \\
\mathrm{ACC}=\frac{\mathrm{TP}+\mathrm{TN}}{\mathrm{TP}+\mathrm{TN}+\mathrm{FP}+\mathrm{FN}},
\end{gathered}
$$

where: TP (true positive) and FP (false positive) are the numbers of foreground image reconstruction pixels (black pixels, pixels of the reconstructed object) consistent with model object's pixels and inconsistent with model object's pixels, respectively; TN (true negative) and FN (false negative) are the numbers of background image reconstruction pixels (white pixels) consistent with model background pixels and inconsistent with model background pixels, respectively.

Besides a confusion matrix approach, others measures are also used to evaluate the similarity of two images, e.g. pixel-to-pixel matching (MPxP), peak signal-to-noise ratio (PSNR) and correlation (COR). MPxP is the method in which each pixel from reconstructed image is compared to the corresponding pixel from the original image. Secondly, peak signal-to-noise ratio (PSNR) is the image quality measure which is simple to calculate, has clear physical measuring but does not match well with the human perception. In practice, the higher PSNR generally the higher image reconstruction quality.
The PSNR is defined as (in $\mathrm{dB}$ ) [4]:

$$
\mathrm{PSNR}=20 \log _{10}\left(\frac{\mathrm{MAX}}{\sqrt{\mathrm{MSE}}}\right)
$$

Where: MAX is the maximum possible pixel value of the image, MSE is the mean squared error.

Lastly, correlation (COR) is the Pearson correlation coefficient. COR is used to measure of the linear correlation between the reconstructed image and the original image of an object as a measurement of the similarity of these two images. In this case, COR is defined as [2-3]:

$$
\mathrm{COR}=\frac{\sum_{m} \sum_{n}[f(m+i, n+j)-\bar{f}][g(m, n)-\bar{g}]}{\sqrt{\sum_{m} \sum_{n}[f(m+i, n+j)-\bar{f}]^{2} \sum_{m} \sum_{n}[g(m, n)-\bar{g}]^{2}}}
$$

Where: $f(m, n)$ is the pixel intensity at a point $(m, n)$ in the original image, $g(m, n)$ is $)$ is the pixel intensity at a point $(m, n)$ in the reconstructed image, $\bar{f}$ and $\bar{g}$ are mean values of the intensity of the images $f$ and $g$, respectively.

\section{Study}

The MAT-MI forward problem has been performed with the help of Comsol Multiphysics based on the finite element method (FEM). In order to reconstruct the acoustic source as the Lorentz force divergence, i.e. $\nabla \cdot\left(\boldsymbol{J} \times \boldsymbol{B}_{0}\right)$, the time reversal algorithm has been used. It should be noted, that the layers are acoustically homogeneous without any reflections, dispersion and attenuation. Moreover, all the studies are ideal and therefore the recorded signals are considered as a noise-free.

The original images of the two exemplary objects under test are shown in Fig. 3. On the left, the so-called a simple-shaped object (hereinafter referred to as a simple object), and to the right a compound-shaped object (hereinafter referred to as a complex object) are presented. The 2D geometry of the simple object consists of two separate spots, while the complex object to be imaged consists of inner and outer layers with the irregular shapes. The electrical conductivity of smaller spot of the simple object and inner layer of the complex object has been set to $8 \mathrm{~S} / \mathrm{m}$. The electrical conductivities of the bigger spot of the simple object and outer layer of the complex object have been set to $6 \mathrm{~S} / \mathrm{m}$. Moreover, the conductivity of the white background in both pictures has been set to $0 \mathrm{~S} / \mathrm{m}$.

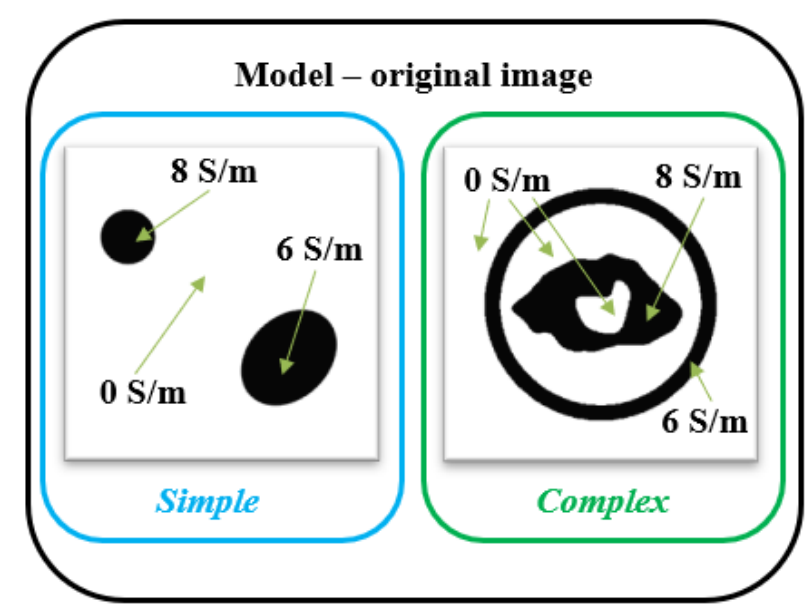

Fig. 3. The objects' view: simple (left, blue frame) and complex (right, green frame)

Results of the reconstruction for four different exemplary number of MP (6, 12, 24 and 36) have been presented in the Fig. 4 and Fig. 5 for the simple and complex object, respectively. In order to reduce the computation time, the size of images has been rescaled to $300 \times 300$ pixels. 


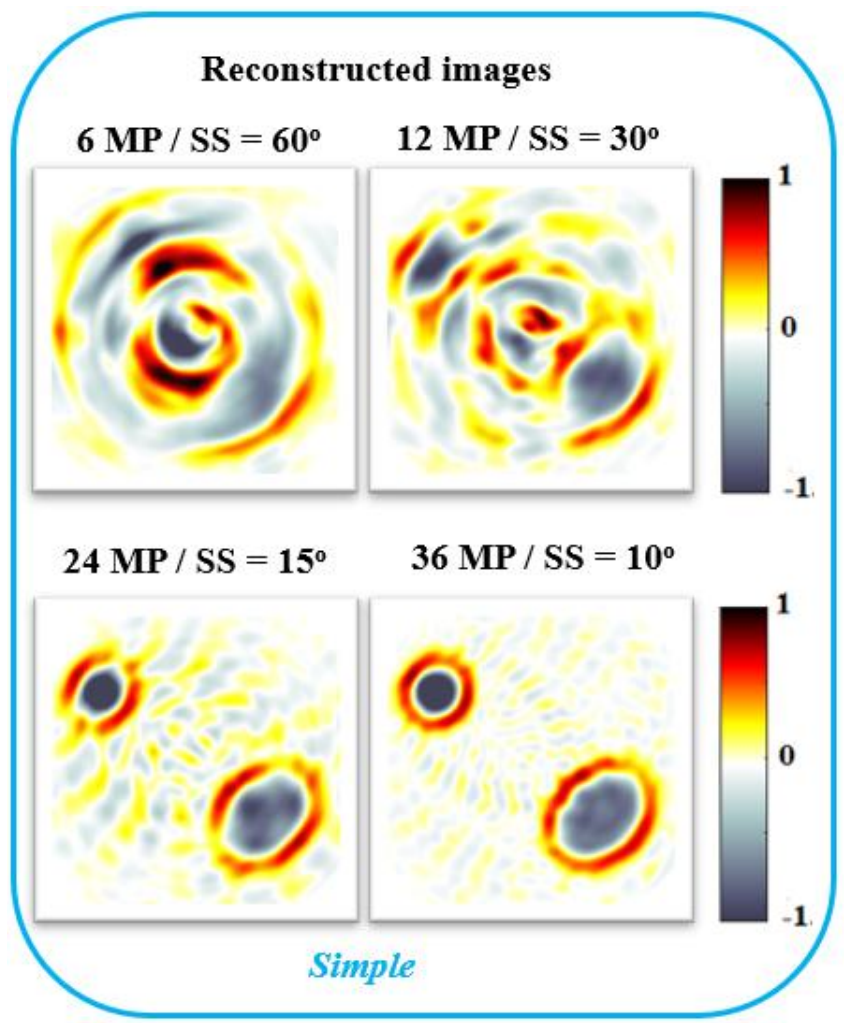

Fig. 4. Normalized acoustic pressure: reconstructed images of the simple object for different number of $M P$

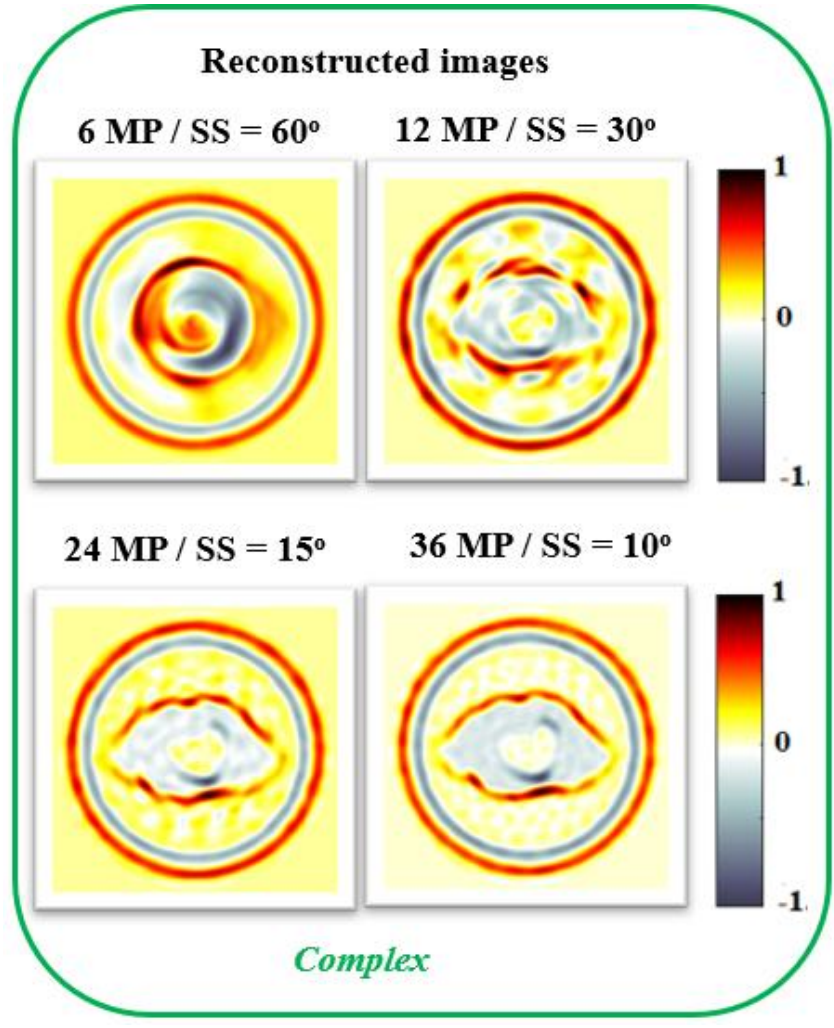

Fig. 5. Normalized acoustic pressure: reconstructed images of the complex object for different number of MP

Next, two groups of the binary images from reconstructed images of the simple and complex object have been made, called 'case A' and 'case B', respectively. The former is made after binarisation from the grayscale image reconstruction of the object with full range of values. In turn, the latter is made after binarisation from the grayscale image reconstruction of the object without positive values. Results of image binarisation of exemplary source images presented already in Fig. 4 and Fig. 5 are shown in Fig. 6.

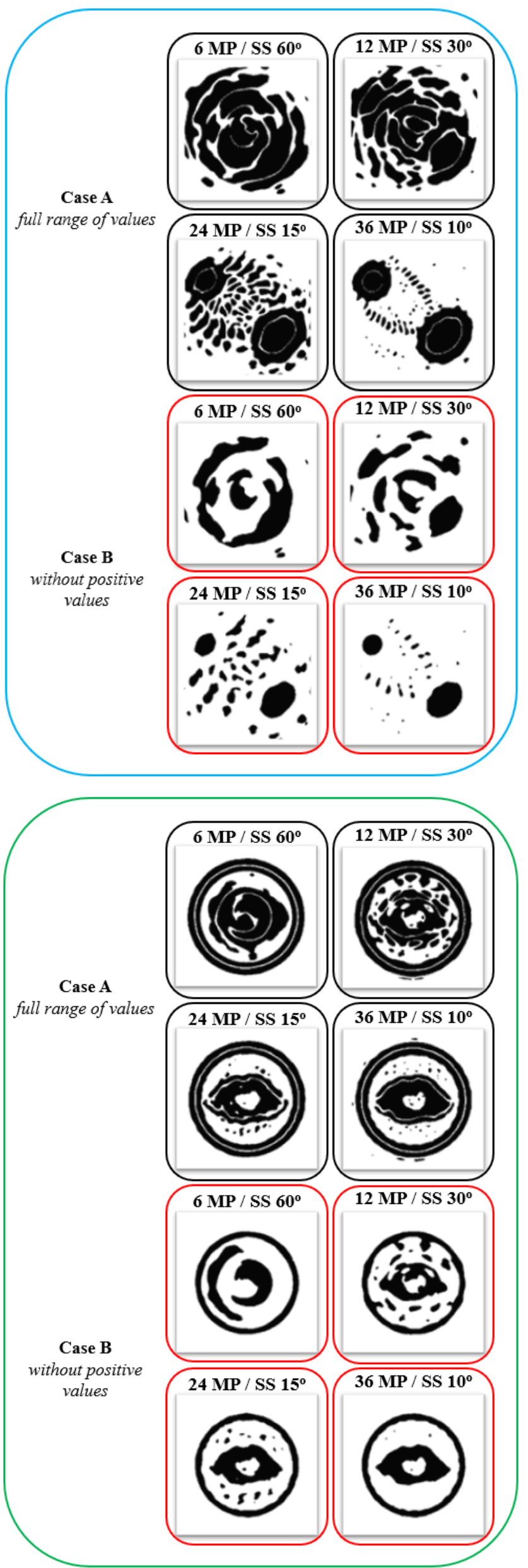

Fig. 6. Exemplary results of binarisation of the simple (blue frame, upper part) and complex (green frame, lower part) object for case $A$ and case $B$ 
The subjective assessment is undoubtedly pointing at a greater similarity of the images in case B to object image than in case A for the both objects. For example, for $6 \mathrm{MP}$ the external ring was properly reconstructed but not much information about the inner part of the complex object is revealed. With $12 \mathrm{MP}$, some of the inner basic features of the complex object start to emerge but still blurring artefacts around and between the inner and outer part of the complex object can be observed. Finally, for 36 MP the reconstructed acoustic source positions almost exactly correspond to the actual locations of the complex object. However, the same thing happens for the simple object. Generally, the greater number of measuring points, the better quality images with less time reversal noise can be observed.

\section{Results}

The straight image comparison (globally) has been chosen which seems best adapted for this case. During the full calculations, the following nine MP numbers have been analysed, i.e.: $6,12,24,36,60,90,120,180$ and 360 . The binary images have been compared without using feature extension (feature comparison). In order to evaluate the reconstruction quality properly, some of the statistical and the other mentioned above indicators have been calculated for the case A and B for the simple and complex object. Curves obtained for PPV and TPR are shown in Fig. 7 and Fig. 8 but values of all calculated indicators for the both objects and the both cases have been summarised in Tab. 1 and Tab. 2.

Table 1. Values of the indicators used to compare the images of the simple object for case A and case B for different number of measuring points MP

Case A of the simple object

\begin{tabular}{|c|c|c|c|c|c|c|c|c|c|}
\hline $\mathrm{SS}\left[{ }^{\circ}\right]$ & MP & PPV & NPV & TPR & TNR & $\mathrm{ACC}$ & MPxP [\%] & PSNR [dB] & COR \\
\hline 60 & 6 & 0.978 & 0.177 & 0.524 & 0.895 & 0.562 & 52.41 & 51.71 & 0.254 \\
\hline 30 & 12 & 0.978 & 0.181 & 0.541 & 0.891 & 0.577 & 54.09 & 51.86 & 0.262 \\
\hline 15 & 24 & 0.990 & 0.238 & 0.657 & 0.941 & 0.689 & 65.68 & 53.15 & 0.369 \\
\hline 10 & 36 & 0.994 & 0.416 & 0.848 & 0.954 & 0.859 & 84.76 & 56.62 & 0.573 \\
\hline 6 & 60 & 0.995 & 0.514 & 0.896 & 0.962 & 0.903 & 89.63 & 58.26 & 0.661 \\
\hline 4 & 90 & 0.995 & 0.518 & 0.898 & 0.963 & 0.905 & 89.78 & 58.33 & 0.665 \\
\hline 3 & 120 & 0.996 & 0.520 & 0.899 & 0.965 & 0.905 & 89.85 & 58.37 & 0.667 \\
\hline 2 & 180 & 0.996 & 0.521 & 0.899 & 0.965 & 0.906 & 89.89 & 58.39 & 0.668 \\
\hline 1 & 360 & 0.996 & 0.521 & 0.899 & 0.965 & 0.906 & 89.90 & 58.39 & 0.669 \\
\hline \multicolumn{10}{|c|}{ Case B of the simple object } \\
\hline $\mathrm{SS}\left[{ }^{\circ}\right]$ & MP & PPV & NPV & TPR & TNR & $\mathrm{ACC}$ & MPxP [\%] & PSNR [dB] & $\mathrm{COR}$ \\
\hline 60 & 6 & 0.954 & 0.261 & 0.783 & 0.671 & 0.772 & 78.33 & 54.54 & 0.312 \\
\hline 30 & 12 & 0.958 & 0.306 & 0.823 & 0.686 & 0.809 & 82.28 & 55.31 & 0.366 \\
\hline 15 & 24 & 0.959 & 0.398 & 0.884 & 0.671 & 0.862 & 88.43 & 56.75 & 0.445 \\
\hline 10 & 36 & 0.963 & 0.800 & 0.981 & 0.668 & 0.949 & 98.09 & 61.04 & 0.806 \\
\hline 6 & 60 & 0.963 & 1.000 & 1.000 & 0.665 & 0.966 & 99.89 & 62.78 & 0.867 \\
\hline 4 & 90 & 0.963 & 1.000 & 1.000 & 0.664 & 0.966 & 99.89 & 62.78 & 0.869 \\
\hline 3 & 120 & 0.963 & 1.000 & 1.000 & 0.664 & 0.966 & 99.89 & 62.78 & 0.869 \\
\hline 2 & 180 & 0.963 & 1.000 & 1.000 & 0.665 & 0.966 & 99.89 & 62.78 & 0.872 \\
\hline 1 & 360 & 0.963 & 1.000 & 1.000 & 0.665 & 0.966 & 99.89 & 62.78 & 0.872 \\
\hline
\end{tabular}

Table 2. Values of the indicators used to compare the images of the complex object for case A and case B for different number of measuring points MP

Case A of the complex object

\begin{tabular}{|c|c|c|c|c|c|c|c|c|c|}
\hline $\mathrm{SS}\left[{ }^{\circ}\right]$ & MP & PPV & NPV & TPR & TNR & $\mathrm{ACC}$ & MPxP [\%] & PSNR [dB] & COR \\
\hline 60 & 6 & 0.945 & 0.476 & 0.733 & 0.851 & 0.759 & 73.32 & 54.32 & 0.496 \\
\hline 30 & 12 & 0.938 & 0.466 & 0.729 & 0.831 & 0.752 & 72.88 & 54.18 & 0.475 \\
\hline 15 & 24 & 0.942 & 0.538 & 0.797 & 0.829 & 0.804 & 79.69 & 55.21 & 0.548 \\
\hline 10 & 36 & 0.955 & 0.555 & 0.802 & 0.866 & 0.816 & 80.22 & 55.49 & 0.583 \\
\hline 6 & 60 & 0.956 & 0.566 & 0.810 & 0.868 & 0.823 & 81.04 & 55.65 & 0.594 \\
\hline 4 & 90 & 0.956 & 0.560 & 0.805 & 0.870 & 0.819 & 80.48 & 55.56 & 0.590 \\
\hline 3 & 120 & 0.956 & 0.566 & 0.810 & 0.870 & 0.823 & 81.00 & 55.66 & 0.596 \\
\hline 2 & 180 & 0.956 & 0.568 & 0.811 & 0.870 & 0.824 & 81.11 & 55.68 & 0.597 \\
\hline 1 & 360 & 0.957 & 0.568 & 0.811 & 0.871 & 0.824 & 81.11 & 55.69 & 0.598 \\
\hline \multicolumn{10}{|c|}{ Case B of the complex object } \\
\hline $\mathrm{SS}\left[{ }^{\circ}\right]$ & MP & PPV & NPV & TPR & TNR & $\mathrm{ACC}$ & $\mathrm{MPxP}[\%]$ & PSNR [dB] & COR \\
\hline 60 & 6 & 0.912 & 0.726 & 0.926 & 0.686 & 0.873 & 92.61 & 57.08 & 0.624 \\
\hline 30 & 12 & 0.925 & 0.771 & 0.938 & 0.735 & 0.893 & 93.77 & 57.82 & 0.684 \\
\hline 15 & 24 & 0.946 & 0.876 & 0.967 & 0.806 & 0.932 & 96.74 & 59.78 & 0.797 \\
\hline 10 & 36 & 0.950 & 0.946 & 0.987 & 0.819 & 0.950 & 98.67 & 61.10 & 0.850 \\
\hline 6 & 60 & 0.953 & 0.950 & 0.988 & 0.830 & 0.953 & 98.77 & 61.37 & 0.859 \\
\hline 4 & 90 & 0.952 & 0.952 & 0.988 & 0.827 & 0.952 & 98.81 & 61.35 & 0.858 \\
\hline 3 & 120 & 0.954 & 0.952 & 0.988 & 0.831 & 0.953 & 98.80 & 61.43 & 0.861 \\
\hline 2 & 180 & 0.954 & 0.952 & 0.988 & 0.832 & 0.954 & 98.81 & 61.46 & 0.862 \\
\hline 1 & 360 & 0.954 & 0.952 & 0.988 & 0.831 & 0.953 & 98.82 & 61.48 & 0.865 \\
\hline
\end{tabular}

The results present the high similarity of the compared binary images in both cases for the both objects. However, the lesser difference between PPV and TPR for case B than case A indicates that the cut off of positive values from the grayscale image reconstruction is resulted in a distinct improvement in the match of the reconstruction to the model. Significant image reconstruction improvement takes place when the number of measuring points begins by 36 for case $\mathrm{A}$ and case $\mathrm{B}$ also for the both objects, respectively. What is more, further increment of measuring points' number does not change the image crucially. 


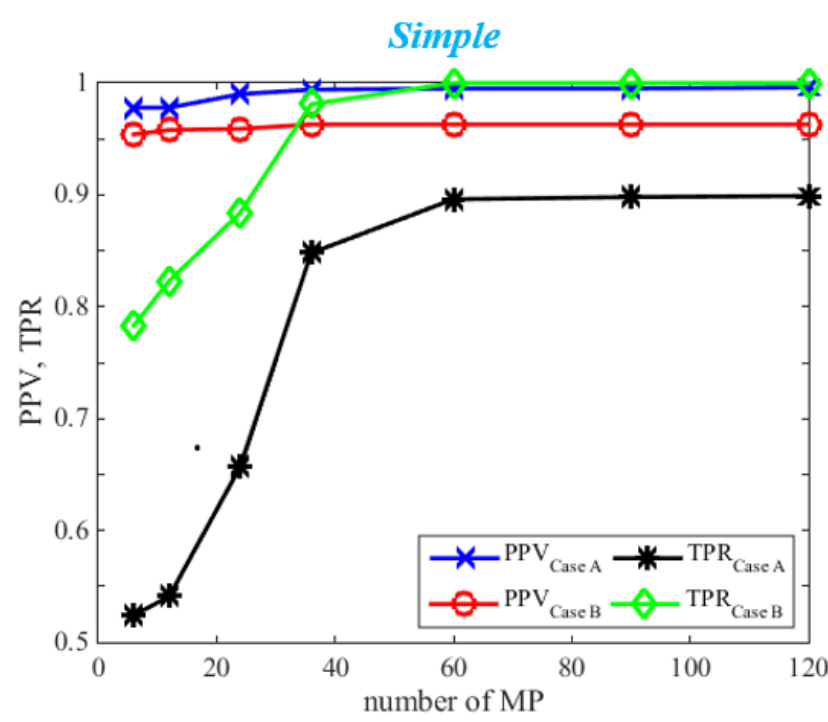

Fig. 7. Value of some confusion matrix indicators obtained for the case A and case $B$ for the simple object

\section{Complex}

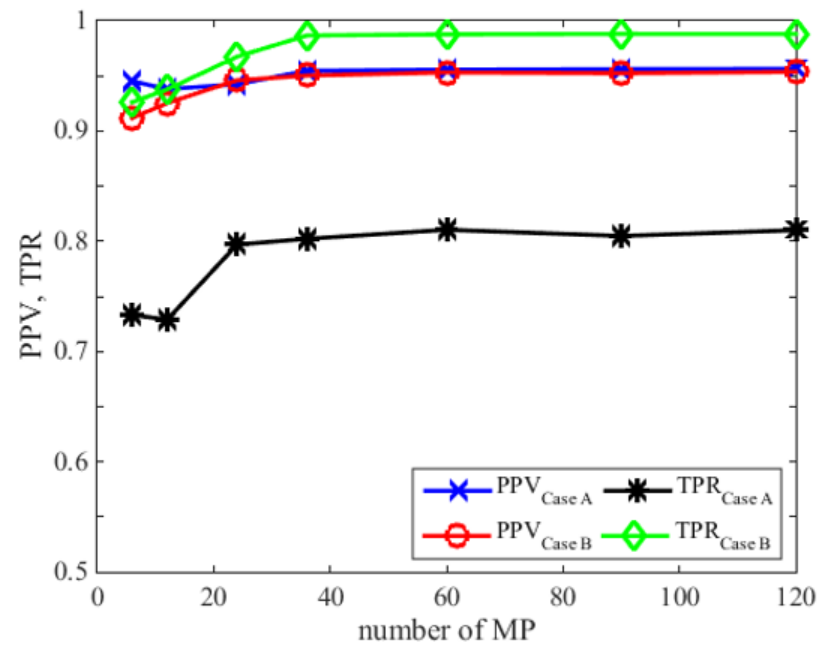

Fig. 8. Value of some confusion matrix indicators obtained for the case A and case $B$ for the complex object

Taking into account three other indicators i.e. pixel-to-pixel matching (MPxP), PSNR and correlation (COR), it can be observed that the results present the great similarity of the compared binary images in both cases for the both objects. As in previous situation (statistical approach), significant image reconstruction improvement occurs when the number of measurement points starts at 36 for both cases also for the both objects. The high values of the indicators for the both cases are due to the fact that the images are compared globally. In addition, large fragments of images near their edges, consisting only of pixels of white colour, also have a large share in inflating the values. Another element that enhances this effect is the lack of a large number of smaller sized artefacts that were cleared during the binarisation.

\section{Conclusions}

In this paper, the influence of MAT-MI scanning resolution on the image reconstruction quality has been studied in detail. In order to evaluate properly the image reconstruction quality, the set of quality indicators has been used. The main task of the indicators is to determine the perceived image quality automatically allowing to benchmark and to optimize scanning resolution and parameter settings in the simulations studies. The information obtained after the simulation tests will allow for accurate matching of the experimental conditions and to properly calibrate the measuring system. Taking into account the subjective and objective assessment of image reconstruction quality, among all the indicators we used to determine the similarity between the reconstructed image and the original image, the correlation gives the best results.

It should be noted that the obtained values of the indicators depend on the resolution of the compared images. However, this resolution is related to the sampling time occurring in the MATMI forward problem. This aspect will be studied in the next article.

\section{References}

[1] Baudrier E., Nicolier F., Millon G., Ruan S.: Binary-image comparison with local dissimilarity quantification. Pattern Recognition 41/2008, 1461-1478, [doi:10.1016/j.patcog.2007.07.011].

[2] Bourke. P.: Cross Correlation. Auto Correlation and 2D Pattern Identification. Research Paper. Oxford University, Oxford 1996.

[3] Fastowicz J., Bąk D., Mazurek P., Okarma K.: Estimation of Geometrica Deformation of 3D Prints Using Local Cross-Correlation and Monte Carlo Sampling. Advances in Intelligent Systems and Computing 681/2018 [DOI: 10.1007/978-3-319-68720-9_9].

[4] Lech P., Okarma K.: Optimization of the Fast Image Binarisation Method Based on the Monte Carlo Approach. Elektronika ir Elektrotechnika 20/2014, 63-66 [DOI: $10.5755 / \mathrm{j} 01$.eee.20.4.6887].

[5] Li X., Yu K., He B.: Magnetoacoustic tomography with magnetic induction (MAT-MI) for imaging electrical conductivity of biological tissue: a tutoria review. Physics in Medicine \& Biology 61/2016, 249-270 [DOI: 10.1088/00319155/61/18/R249].

[6] Michalak. H., Okarma K.: Region Based Approach for Binarisation of Degraded Document Images. Advances in Soft and Hard Computing 889/2019, 433-444 [DOI: 10.1007/978-3-030-03314-9_37].

[7] Rymarczyk T., Kłosowski G., Kozłowski E.: A non-destructive system based on electrical tomography and machine learning to analyze the moisture of buildings. Sensors 18(7)/2018, 2285 [DOI: 10.3390/s18072285].

[8] Stawicki K., Gratkowski S., Komorowski M., Pietrusewicz T.: A new transducer for magnetic induction tomography. IEEE Transactions on Magnetics 45/2009, 1832-1835 [DOI: 10.1109/TMAG.2009.2012799].

[9] Wang Z., Sheikh H. R., Bovik A.: Objective video quality assessment. Chapter 41 in The Handbook of Video Databases: Design and Application, Furht B. and Marqure O., CRC Press 2003, 1041-1078.

[10] Zywica A. R.,: Magnetoacoustic tomography with magnetic induction for biological tissue imaging: numerical modelling and simulations. Archives of Electrical Engineering 65(1)/2015, 141-150 [DOI: 10.1515/aee-2016-0011]

\section{M.Sc. Adam Ryszard Zywica \\ e-mail: adam.zywica@zut.edu.pl}

Adam Ryszard Zywica received the M.Sc. degree in Electrical Engineering Faculty from West Pomeranian University of Technology, Szczecin, Poland in 2014. Since October 2014, he is a Ph.D. student at the Department of Electrical and Computer Engineering, Electrical Engineering Faculty, West Pomeranian University of Technology, Szczecin, Poland. His main research interests include non-destructive testing of materials. His hobbies are chess, modern history, football, tennis

ORCID ID: 0000-0003-2598-0052

\section{D.Sc. Marcin Ziolkowski}

e-mail: marcin.ziolkowski@zut.edu.pl

Marcin Ziolkowski received M.Sc., Ph.D. and D.Sc. (Habilitation) degrees in Electrical Engineering from the Szczecin University of Technology, Szczecin, Poland and West Pomeranian University of Technology, Szczecin, Poland in 2001, 2006 and 2012, respectively. Since 2008, he has been working with the Department of Electrical and Computer Engineering, Electrical Engineering Faculty, West Pomeranian University of Technology, Szczecin, Poland. His main research interests include numerical calculations and visualization of EM fields, inverse problems, electromagnetic field shielding and nondestructive testing of materials.

ORCID ID: 0000-0002-2773-2565

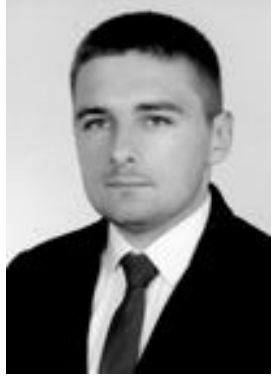

przyjęto do druku/accepted: 06.12.2019 